\title{
SIBRAGEC

\section{DIRETRIZES DE FISCALIZAÇÃO DO PLANEJAMENTO E CONTROLE DE PRAZOS PARA CONTRATANTES DE OBRAS DO SEGMENTO VAREJISTA FARMACÊUTICO ${ }^{1}$}

\author{
SANTOS, Lorenna Araújo dos (1); BÖES, Jeferson Spiering (2) \\ (1) Faculdade Ari de Sá, lorenna.santosaraujo@ hotmail.com, (2) Faculdade Ari de Sá, \\ boes.jeferson@gmail.com
}

\begin{abstract}
RESUMO
Ao longo dos últimos anos, o mercado varejista farmacêutico vem ganhando grande destaque no cenário econômico nacional. Para acompanhar este crescimento, se faz necessário um grande volume de obras novas e reformas, a fim de ofertar a infraestrutura física necessária para suprir esta nova demanda. As obras do segmento varejista farmacêutico apresentam singularidades, no que se refere à prazos reduzidos, formatos de contratação e fiscalização. Muitas vezes, os setores responsáveis são enxutos e enfrentam grandes volumes de obras simultâneas, carecendo de recursos metodológicos e ferramentas que auxiliem no cumprimento das atividades. $O$ presente trabalho tem por objetivo, desenvolver um conjunto de diretrizes que auxiliem o planejamento e controle de prazos para contratantes de obras do segmento varejista farmacêutico. O presente estudo está enquadrado como uma pesquisa do tipo Design Science Propositiva, que tem por objetivo somente propor o artefato, sem validá-lo. Como principais contribuições, destaca-se a relevância da empresa analisada, possuindo 1.100 lojas em todo Brasil, com um volume de 245 obras em andamento no período do referido estudo, a identificação das principais problemáticas relatadas pelo setor de engenharia, e o desenvolvimento de diretrizes que auxiliem o processo.
\end{abstract}

Palavras-chave: Fiscalização de Obras, Planejamento de Obras, Gestão de Obras, Obras Varejistas, Varejo Farmacêutico.

\begin{abstract}
Over the past few years, the pharmaceutical retail market has gained great prominence in the national economic scenario. To keep up with this growth, a large volume of new works and reforms is necessary, in order to offer the physical infrastructure necessary to meet this new demand. The works in the pharmaceutical retail segment present singularities, with regard to reduced deadlines, contracting and inspection formats. Often, the responsible sectors are lean and face large volumes of simultaneous works, lacking methodological resources and tools to assist in carrying out the activities. The present work aims to develop a set of guidelines that assist in the planning and control of deadlines for construction contractors in the pharmaceutical retail segment. The present study is framed as a research of the Propositive Design Science type, which aims only to propose the artifact, without validating it. As main contributions, the relevance of the analyzed company stands out, having 1,100 stores throughout Brazil, with a volume of 245 works in progress during the period of the aforementioned study, the identification of the main problems reported by the engineering sector, and the development of guidelines that help the process.
\end{abstract}

Keywords: Pharmaceutical Retail Segment. Supervision of construction. Planning. Control of Deadlines. Construction

\footnotetext{
${ }^{1}$ SANTOS, L. A. dos; BÖES, J. S. Diretrizes de fiscalização do planejamento e controle de prazos para contratantes de obras do segmento varejista farmacêutico. In: SIMPÓSIO BRASILEIRO DE GESTÃO E ECONOMIA DA CONSTRUÇÃO, 12., 2021, Maceió. Anais[...] Porto Alegre: ANTAC, 2021. p.1-8. Disponível em: https://eventos.antac.org.br/index.php/sibragec/article/view/435. Acesso em: 2 out. 2021
} 


\section{INTRODUÇÃ̃O}

A gestão das construções é um componente crítico para a execução bem-sucedida. (KIM et al., 2013), sendo considerada uma indústria que possui informação intensiva e que necessitam ser transferidas e trocadas durante o ciclo de vida do projeto (CHEN; KAMARA, 2011).

O atraso de obras é um dos maiores problemas de relevância na indústria da construção (MAHAMID; BRULAND; DMAIDI, 2011), sendo motivo de estudo na literatura nacional (MAUÉS et al., 2019; CRUZ; SANTOS; MENDES, 2018; ALVARENGA et al., 2021). O planejamento está diretamente relacionado ao custo, prazo e qualidade, motivos estes, que afetam o prazo de uma obra, consequentemente, afetando o custo final (ALVARENGA et al., 2021).

No mercado varejista cada vez mais competitivo, o tempo passar a ser um fator de diferenciação em qualquer empresa do setor frente à sua concorrência, sendo a construção dos seus pontos de venda, passa a ter uma grande importância. (SU, 2019). As obras do segmento varejista farmacêutico possuem suas próprias peculiaridades, diferenciando-se no que tange ao prazo, modalidade de contratação e fluxos de informações, em relação as demais tipologias de obras. (SU, 2019). Frente ao exposto, o presente trabalho se propõe a identificar as principais dificuldades do planejamento e controle de prazos para contratantes de obras do segmento varejista, como também, propor um conjunto de diretrizes que auxiliem o processo.

\section{METODOLOGIA}

O presente estudo possui como estratégia de pesquisa a Design Science Research (DSR), que propõe o desenvolvimento de artefatos (DRESCH; LACERDA; ANTUNES JUNIOR, 2015), no caso, as Diretrizes de Planejamento e Controle de Prazo, sendo seus objetivos exploratórios (GIL, 2002) e de natureza qualitativa (SU, 2019).

Cândido, Lima e Barros Neto (2014), propõem uma pré-classificação de pesquisas do tipo Design Science (DS), em relação à proposição (ou não) de um artefato versus a validação (ou não) do mesmo, podendo ser: DS Plena, DS Propositiva ou DS Avaliativa. Neste contexto, o presente trabalho se enquadra no modelo de DS Propositiva, tendo como objetivo somente propor o artefato, sem validá-lo.

O delineamento do trabalho está organizado em 3 fases: Compreensão, Desenvolvimento da Solução e Análise e Reflexão (HOLMSTRÖM; KETOKIVI; HAMERI, 2009), sendo executada através de 4 etapas, conforme ilustra o quadro 1.

Quadro 1 - Fases e etapas do delineamento
\begin{tabular}{|c|l|}
\hline $\begin{array}{c}\text { Fase da DSR } \\
\text { (HOLMSTROM; KETOJIVI; HAMERI, 2009) }\end{array}$ & \multicolumn{1}{c|}{ Etapas do Estudo } \\
\hline $\begin{array}{c}\text { Fase 1 } \\
\text { Compreensão }\end{array}$ & (i) Pesquisa Bibliográfica \\
\cline { 2 - 3 } & $\begin{array}{l}\text { (ii) Identificação das dificuldades da fiscalização do planejamento e } \\
\text { controle de prazos }\end{array}$ \\
\hline $\begin{array}{c}\text { Fase 2 } \\
\text { Desenvolvimento da Solução }\end{array}$ & (iii) Desenvolvimento das diretrizes \\
\hline $\begin{array}{c}\text { Fase 3 } \\
\text { Análise e Reflexão }\end{array}$ & (iv) Validação das diretrizes com especialistas \\
\hline
\end{tabular}

Fonte: autores.

\subsection{Pesquisa Bibliográfica}

A pesquisa bibliográfica consistiu em promover uma fundamentação e compreensão acerca da literatura, de forma a buscar o entendimento do tema de pesquisa, priorizando 
estudos publicados em periódicos (Ambiente Construído, Gestão \& Produção, Produção Online, PARC) e congressos nacionais (ENTAC, SIBRAGEC, CONBREPRO, ENEGEP).

\subsection{Identificação das dificuldades da Fiscalização do Planejamento e Controle de prazos}

Para realizar a identificação das dificuldades, definiu-se uma empresa para estudo de caso (YIN, 2010), que apresentasse um volume representativo de obras do segmento varejista farmacêutico.

A empresa A possui atuação em todo território nacional, através de 1.100 unidades, com atuação há mais de 35 anos. Durante o ano de 2019, período de realização deste estudo, a Empresa A possuía 245 obras, entre reformas e novas unidades em todo Brasil. Para limitação do presente estudo, focou-se em analisar as problemáticas e propor diretrizes para obras de Reformas. A escolha deste segmento se deve em virtude as particularidades que envolvem as obras de reformas, a ausência de informações e o rápido período de execução.

De forma a promover a identificação das dificuldades da fiscalização do planejamento e controle de prazos por parte dos contratantes de obras, em relação as empresas construtoras, desenvolveu-se um instrumento de pesquisa, tipo Questionário com questões abertas e fechadas (RICHARDSON, 2011; CHIZZOTI, 2011).

O questionário foi estruturado em duas partes: (i) Caracterização da amostra; com 4 questões, e, (ii) Planejamento, Fiscalização do Planejamento e Controle de Prazos; com 21 questões. Após concepção da primeira versão, o mesmo foi validado juntamente com um especialista e posteriormente, aplicado de modo Teste-Piloto em dois representantes da Empresa A. Por fim, foram realizados os devidos ajustes e desenvolvida a versão final.

Foi encaminhado a 6 membros do setor de Engenharia da Empresa A, pois os mesmos são os responsáveis pela contratação, planejamento, controle e fiscalização das obras. $\mathrm{O}$ questionário foi disponibilizado através de formulário eletrônico tipo Google Forms.

\subsection{Desenvolvimento das diretrizes}

Com a aplicação dos questionários, realizou-se o processamento dos dados, de forma a identificar as problemáticas no planejamento e controle de prazos. As respostas foram sintetizadas e divididas conforme temáticas em comum, totalizando 8 temáticas. $\mathrm{O}$ desenvolvimento das diretrizes teve como suporte a pesquisa bibliográfica realizada, como também, as observações, relatos obtidos durante a pesquisa.

\subsection{Validação das diretrizes}

Após desenvolvido a primeira versão das diretrizes, as mesmas foram apresentadas com o intuito de haver a validação junto com especialistas, através de um grupo focal (OLIVEIRA; LEITE FILHO; RODRIGUES, 2007). A partir das contribuições realizadas, as diretrizes foram aperfeiçoadas. 


\section{RESULTADOS}

O questionário foi aplicado em 6 stakeholders da Empresa A, sendo 2 Gerentes e 4 Coordenadores, onde foram elencadas as principais problemáticas encontradas no cotidiano de trabalho, sendo organizadas em áreas temáticas, conforme ilustra os quadros 2.

Quadro 2 - Barreiras encontradas

\begin{tabular}{|c|c|c|}
\hline$\#$ & Dificuldade & Problemática \\
\hline 1 & $\begin{array}{l}\text { Disparidade do nível de escolaridade dos } \\
\text { profissionais do setor de engenharia. }\end{array}$ & $\begin{array}{l}\text { Considerando o cargo de Coordenador de Obras: } \\
\text { somente } 1 \text { (um) dos participantes tinha ensino superior } \\
\text { completo, } 2 \text { (dois) possuíam nível técnico e 1(um) deles } \\
\text { apenas o ensino médio completo. } \\
\text { Apesar da diferencia na formação acadêmica e } \\
\text { consequentemente habilitação profissional, os } \\
\text { envolvidos apresentam as mesmas responsabilidades. }\end{array}$ \\
\hline 2 & $\begin{array}{l}\text { Ineficiência do processo adotado na etapa } \\
\text { de Planejamento das Reformas. }\end{array}$ & $\begin{array}{l}\text { Incompatibilidades entre os projetos executivos e as } \\
\text { características reais da edificação, além da base } \\
\text { desatualizada de projetos das filiais, o que gerava uma } \\
\text { demora na elaboração de layouts, análise dos } \\
\text { orçamentos apresentados pelas construtoras e na } \\
\text { definição do Cronograma Físico-Financeiro. }\end{array}$ \\
\hline 3 & & $\begin{array}{l}\text { Escassez de vistorias presenciais às obras, oriundo do } \\
\text { grande volume de reformas simultâneas, somado pelas } \\
\text { distâncias geográficas entre as obras, uma vez que são } \\
\text { a nível nacional, como também o baixo efetivo do setor } \\
\text { de Engenharia, acarretando erros executivos, } \\
\text { retrabalhos e má qualidade dos serviços prestados. }\end{array}$ \\
\hline 4 & $\begin{array}{l}\text { Ineficiência do processo adotado para a } \\
\text { etapa de Fiscalização do Planejamento das }\end{array}$ & $\begin{array}{l}\text { Interferência na gestão da obra pelo setor Operacional } \\
\text { e Administração das lojas. Devido estes setores estarem } \\
\text { fisicamente próximos das obras e a ausência física do } \\
\text { setor de engenharia, há intervenção, alterações do } \\
\text { processo, prazo e qualidade, mesmo estes, não } \\
\text { possuírem habilitação, competências e } \\
\text { responsabilidades para esta tomada de decisão. Tal } \\
\text { ação, promove um desgaste interpessoal entre o setor } \\
\text { de engenharia da Empresa A e as construtoras } \\
\text { contratadas. }\end{array}$ \\
\hline 5 & & $\begin{array}{l}\text { Não cumprimento do Caderno de Obras, por parte da } \\
\text { construtora contratada, substituindo materiais } \\
\text { especificados por alternativos, sem autorização do } \\
\text { contratante. Tal ação, ocorre em diversos retrabalhos, } \\
\text { sendo determinado a substituição destes materiais pelos } \\
\text { especificados. } \\
\text { O retrabalho impacta significativamente no } \\
\text { atendimento dos prazos, uma vez que o timing desta } \\
\text { modalidade de obra é reduzido. } \\
\text { Em situações de impossibilidade técnica de } \\
\text { substituição dos materiais, devido ao cumprimento do } \\
\text { prazo de obra para inauguração, acaba-se aceitando no } \\
\text { checklist de recebimento de obra, sem qualquer } \\
\text { advertência ou punição à construtora. }\end{array}$ \\
\hline 6 & \multirow{3}{*}{ Ineficiência no Controle de Prazos } & $\begin{array}{l}\text { Ausência de informações ou informações } \\
\text { inconsistentes com a realidade do local, acarretando } \\
\text { atrasos na entrega da obra e aumento de custos. }\end{array}$ \\
\hline 7 & & $\begin{array}{l}\text { Ausência de medidas punitivas (multas) as construtoras } \\
\text { que não atendessem os prazos estipulados em contrato. }\end{array}$ \\
\hline 8 & & $\begin{array}{l}\text { Ausência de um banco de dados com retroalimentação } \\
\text { de problemáticas diagnosticadas anteriormente, que } \\
\text { poderiam servir de subsídio para tomadas de decisão e } \\
\text { melhoria do processo. }\end{array}$ \\
\hline
\end{tabular}

Fonte: autores. 
Quadro 2 - Barreiras encontradas (continuação)

\begin{tabular}{|c|c|c|}
\hline$\#$ & Dificuldade & Problemática \\
\hline 9 & Ausência de Treinamentos e Capacitação & $\begin{array}{l}\text { Apenas os cargos de Gerentes possuem treinamentos e } \\
\text { capacitações. Os coordenadores que desempenham } \\
\text { funções semelhantes e utilizam as mesmas ferramentas, } \\
\text { não recebiam. No entanto, são os coordenadores que } \\
\text { apresentam maior necessidade de capacitação, tendo } \\
\text { em visto que são os responsáveis pelo operacional do } \\
\text { planejamento e controle. }\end{array}$ \\
\hline 10 & \multirow{3}{*}{$\begin{array}{l}\text { Reuniões periódicas para o alinhamento } \\
\text { das atividades e análise do andamento } \\
\text { físico da reforma. }\end{array}$} & $\begin{array}{l}\text { Grande demanda simultâneas de reformas dificultava o } \\
\text { acompanhamento eficaz do processo. }\end{array}$ \\
\hline 11 & & $\begin{array}{l}\text { Devido ao curto prazo (algumas obras apresentam um } \\
\text { prazo de } 14 \text { dias), as reuniões semanais, acabam sem } \\
\text { surgir efeito. }\end{array}$ \\
\hline 12 & & $\begin{array}{l}\text { Baixo alinhamento nas reuniões, comparado com a } \\
\text { cobrança realizada pela alta direção. }\end{array}$ \\
\hline 13 & & $\begin{array}{l}\text { Confronto de opiniões com o time de operações das } \\
\text { filiais no processo como ponto crítico. }\end{array}$ \\
\hline 14 & Relacionamento Contratante e Contratada. & $\begin{array}{l}\text { O relacionamento inicialmente é considerado } \\
\text { harmonioso, mas ao extrapolar o prazo inicial } \\
\text { acordado, há uma ausência de informações, baixo inter- } \\
\text { relacionamento e aderência às cobranças do Contratado } \\
\text { por parte da Contratante. }\end{array}$ \\
\hline 15 & $\begin{array}{l}\text { Conhecimento de princípios e } \\
\text { metodologias ligadas ao Planejamento, } \\
\text { Gerenciamento e Controle de Prazos. }\end{array}$ & $\begin{array}{l}\text { Baixo conhecimento por parte da Empresa A acerca de } \\
\text { princípios, metodologias ligadas ao planejamento, } \\
\text { gerenciamento de obras e controle de prazos. Devido ao } \\
\text { alto volume de obras, tornava-se complicado a adoção } \\
\text { de princípios e desenvolver/criar novas metodologias. }\end{array}$ \\
\hline
\end{tabular}

Fonte: autores.

Tomando como base as problemáticas apresentadas acima, foi elaborado um conjunto de diretrizes, de modo a propor a aplicação de conceitos, princípios e metodologias voltadas à gestão de projetos e melhoria contínua do processo, bem como à implantação de estratégias que possibilitem uma melhoria nas trocas e atualizações de informações da obra durante todo o processo, conforme ilustra os quadros 3.

\section{Quadro 3 - Diretrizes para a fiscalização do Planejamento e Controle de Prazos}

\begin{tabular}{|c|l|}
\hline$\#$ & \multicolumn{1}{c|}{ Diretriz Proposta } \\
\hline 1 & $\begin{array}{l}\text { Se utilizando de um dos princípios do Lean Construction, que prescreve a melhoria contínua do } \\
\text { processo, e aplicando-o a uma das suas peças-chave; o colaborador; percebe-se que há inúmeros } \\
\text { benefícios em incentivar o contínuo aprendizado e aprimoramento profissional dos funcionários, que } \\
\text { passarão a dispor de mais conhecimento técnico acerca dos processos, e poderão propor melhorias } \\
\text { a este, além de se sentirem motivados a crescer profissionalmente. }\end{array}$ \\
\hline 2 & $\begin{array}{l}\text { Diante desta problemática, a metodologia BIM surge como uma estratégia de melhoria a ser } \\
\text { considerada, visto que, ela possibilita a integração de todas as etapas do processo construtivo, } \\
\text { permitindo que incompatibilidades de projeto sejam facilmente detectadas e rapidamente } \\
\text { solucionadas, e que a geração de dados e elaboração de relatórios e acompanhamentos sejam mais } \\
\text { confiáveis. }\end{array}$ \\
\hline 3 & $\begin{array}{l}\text { Esta problemática pode se justificar pelos elevados custos em promover viagens periódicas aos } \\
\text { Coordenadores, para a realização de vistoria das Reformas em andamento, porém, existem inúmeras } \\
\text { maneiras de se promover o acompanhamento de obras à distância, (i) por meio de aplicativos que } \\
\text { fornecem imagens e dados atualizadas da obra, ou (ii) a partir da implantação de equipes regionais } \\
\text { de engenharia, para a realização de tais atividades in loco. Nesta etapa, deve-se aplicar os } \\
\text { conhecimentos apresentados nos tópicos que tratam da abordagem PMBOK e da metodologia BIM. }\end{array}$ \\
\hline
\end{tabular}

Fonte: autores. 
Quadro 3 - Diretrizes para a fiscalização do Planejamento e Controle de Prazos (continuação)

\# $\quad$ Diretriz Proposta

4 Como sugestão para a resolução desta problemática, temos que: (i) ao implantar equipes regionais de engenharia por todo o território nacional, conforme sugerido no item 3, a interação entre os envolvidos do setor de engenharia e do time de operações passaria a ser mais estreita, facilitando a comunicação e resolução de problemáticas ou dúvidas que surgissem ao longo do processo de Fiscalização do Planejamento, ou (ii) aplicando-se as premissas relacionadas ao Gerenciamento das Comunicações do Projeto e de Gerenciamento das Partes Interessadas do Projeto, levantadas através da abordagem PMBOK, deveria-se realizar uma reestruturação das funções cabíveis a cada setor, dando mais autonomia e voz aos gerentes do setor de engenharia, no que diz respeito às decisões estratégicas para o bom andamento da Reforma.

5 Nesta problemática, podemos perceber a importância da comunicação e do alinhamento entre as equipes envolvidas, além da presença diária de um responsável técnico do setor de engenharia no local da Reforma. Se tratando de materiais de acabamento, é compreensível que possam faltar no mercado, por algum motivo, mas isso não justifica a aquisição e aplicação de materiais fora do padrão sem uma prévia autorização do contratante. Portanto, sendo implementadas melhorias com relação à comunicação entre os envolvidos e o aumento da frequência de um responsável técnico no local da Reforma, deveriam ser aplicadas medidas punitivas a qualquer construtor que insistisse em tomar tais decisões.

6 Com relação aos erros de projeto: poderiam ser identificados com antecedência na etapa de planejamento, por meio da aplicação de ferramentas ligadas à metodologia BIM.

Com relação aos erros executivos: costumam estar relacionados à falta de capacitação da mão-deobra e acompanhamento da execução dos serviços por um responsável técnico capacitado. Portanto, cabe ao contratante criar uma base de dados com os tipos de erros e a frequência de suas ocorrências, possibilitando a análise do histórico por construtora responsável, e permitindo uma tomada de decisões para a redução ou erradicação destes.

$7 \quad$ Primeiramente, faz-se necessária uma análise dos motivos que geraram o atraso na entrega da Reforma, visto que, foi citado anteriormente a influência do time de operações em decisões cabíveis somente ao setor de engenharia. Portanto, sendo confirmada a responsabilidade por parte do construtor, tais medidas punitivas deveriam ser aplicadas, principalmente por estarem descritas em contrato firmado por ambas as partes.

8 Se utilizando de alguns dos princípios do Lean Construction, como: (i) aumento da transparência, (ii) foco no controle de todo o processo e (iii) estabelecimento de melhoria contínua ao processo, e da abordagem PMBOK, que apresenta o grupo de processos de monitoramento e controle, que representa o acompanhamento, a análise e o controle do progresso e desempenho do projeto, podemos perceber a importância de se elaborar uma base de dados com as ocorrências pertinentes às atividades atreladas ao controle do prazo de execução das Reformas. Portanto, faz-se necessária uma reestruturação das práticas adotadas pelo contratante, visando a implantação de uma base de dados constantemente atualizada, que fornecerá dados importantes aos gestores responsáveis, facilitando a tomada de decisões e implantação de melhorias para as próximas Reformas.

9 É de consenso comum, que a realização de treinamentos e cursos visam o aprimoramento do conhecimento técnico do profissional, principalmente se este for responsável pela base de informações do processo. Portanto, cabe ao contratante reavaliar se tais benefícios; aplicados aos Gerentes; poderiam também ser estendidos aos Coordenadores, visando um aumento da qualidade dos dados fornecidos e uma maior qualificação dos profissionais envolvidos no processo.

10 Essa problemática está relacionada à sobrecarga de atividades aos profissionais envolvidos. Neste contexto, temos duas opções de diretrizes: (i) implementação de ferramentas tecnológicas que auxiliem e facilitem o trabalho dos profissionais envolvidos ou (ii) realização de uma auditoria interna para analisar se esta sobrecarga de atividades apontada no estudo realmente se confirma, sendo confirmada, sugere-se que seja realizada uma redistribuição das atividades, e, se necessário, contratação de mais profissionais para atender a demanda do setor.

11 O acompanhamento do Coordenador responsável deve ser diário, portanto, sendo este mais eficiente, levando em consideração a implantação das diretrizes propostas anteriormente, as reuniões certamente seriam mais produtivas. Porém, precisa-se aprimorar a qualidade e rapidez nas comunicações entre os profissionais envolvidos no processo, facilitando a troca de informações e resoluções de problemáticas que venham a surgir no decorrer do andamento da execução da Reforma.

Fonte: autores. 
Quadro 3 - Diretrizes para a fiscalização do Planejamento e Controle de Prazos (continuação)

\begin{tabular}{|c|l|}
\hline$\#$ & \multicolumn{1}{|c|}{ Diretriz Proposta } \\
\hline 12 & $\begin{array}{l}\text { Profissionais sem o benefício do aprimoramento, por meio de treinamentos e cursos voltados às } \\
\text { ferramentas utilizadas no dia-a-dia, e sobrecarregados com a grande demanda simultâneas de } \\
\text { Reformas, conforme destacado nas problemáticas apresentadas anteriormente, adicionado à falta de } \\
\text { uma comunicação eficaz entre os envolvidos e o acompanhamento superficial durante as reuniões } \\
\text { semanais, são fatores que embasam tal problemática. Portanto, levando em consideração a } \\
\text { implantação das diretrizes propostas anteriormente, esta questão seria mais facilmente solucionada. }\end{array}$ \\
\hline 13 & Analisar as diretrizes propostas no item 4. \\
\hline 14 & $\begin{array}{l}\text { Um bom acompanhamento diário do andamento físico da Reforma, permite uma maior } \\
\text { previsibilidade com relação ao cumprimento ou não do prazo pré-estabelecido para a entrega da } \\
\text { mesma. Portanto, o aprimoramento das comunicações, a realização de vistorias presenciais mais } \\
\text { constantes, uma base de informações diariamente atualizada e a implantação de novas ferramentas } \\
\text { de planejamento, fiscalização e controle das Reformas, seria suficiente para reduzir ou evitar tais } \\
\text { desgastes com os construtores. }\end{array}$ \\
\hline 15 & $\begin{array}{l}\text { A filosofia dos Cinco Sensos está diretamente relacionada à organização e manutenção de um } \\
\text { ambiente de trabalho saudável, enquanto que as demais estratégias apresentadas estão diretamente } \\
\text { relacionadas à reestruturação dos processos, visando sempre uma forma mais eficaz e produtiva de } \\
\text { planejamento, execução, físcalização e controle das atividades. } \\
\text { Tais estratégias de reestruturação dos processos foram aplicadas às diretrizes propostas nos tópicos } \\
\text { anteriores, portanto, percebe-se a importância da busca constante por conhecimento, como forma de } \\
\text { expansão da visão estratégica diante das dificuldades apresentadas no dia-a-dia. Algo que deve ser } \\
\text { buscado tanto pelo profissional; de forma independente; quando pela empresa, visando sempre a } \\
\text { melhoria dos processos aplicados, a manutenção de um ambiente harmonioso e a satisfação das } \\
\text { equipes envolvidas. }\end{array}$ \\
\hline Fon
\end{tabular}

Fonte: autores.

\section{CONSIDERAÇÕES FINAIS}

O presente trabalho visou identificar as principais dificuldades para fiscalização do planejamento e controle de obras de reformas para contratantes de obras do segmento varejista farmacêutico. Ao todo, foram identificadas e catalogadas 15 dificuldades principais, divididas em 8 temáticas, nas quais desenvolveu-se diretrizes que visem auxiliar os contratantes na melhoria dos processos internos.

Conclui-se que apesar das obras do segmento varejista farmacêutico possuírem peculiaridades próprias e muitas vezes, únicas em relação às demais tipologias de obras, as dificuldades podem ser compreendidas como as mesmas das demais tipologias. O que há de diferenciação é a velocidade na tomada de decisão, tendo em vista que os prazos de obra e processo de decisão são muito mais rápidos em relação aos processos tradicionais.

A adoção de fillosofias e metodologias como Lean Construction, PMBOK, Modelagem da Informação na Construção e Metodologias Ágeis, podem contribuir para o processo de gestão das obras deste segmento.

Por fim, vislumbra-se como trabalho futuro, o desenvolvimento de um modelo de gestão envolvendo todas as etapas, iniciando na demanda de reforma, até a gestão do ativo, com enfoque nas peculiaridades do setor e fluxos de informações. 


\section{REFERÊNCIAS}

ALVARENGA, F. C. et al. Alterações de custo e prazo em obras públicas. Ambiente Construído, Porto Alegre, v. 21, n. 1, p. 161-180, jan./mar. 2021.

CÂNDIDO, L. F.; LIMA, S. H. O.; BARROS NETO, J. P. Análise da aplicação da abordagem Design Science em estudos na área de gestão e economia da construção. In: ENCONTRO NACIONAL DOS PROGRAMAS DE PÓS-GRADUAÇÃO E PESQUISA EM ADMINISTRAÇÃO, 38., 2014, Rio de Janeiro. Anais [...]. Rio de Janeiro: ANPAD, 2014.

CHEN, Y.; KAMARA, J. M. A framework for using mobile computing for information management on construction sites. Automation in Construction, v. 20, n. 7, p. 776-788, nov. 2011.

CHIZZOTTI, A. Pesquisa qualitativa em ciências Humanas e Sociais. $4^{\text {a }}$ edição. Petrópolis. Rio de Janeiro: Vozes, 2011.

CRUZ, H. M.; SANTOS, D. G.; MENDES, L. A. Causas da variabilidade do tempo de execução dos processos em diferentes sistemas construtivos. Ambiente Construído, Porto Alegre, v. 18, n. 1, p. 49-65, jan./mar. 2018

DRESCH, A.; LACERDA, D. P.; ANTUNES JÚNIOR, J. A. V. Design Science Research: método de pesquisa para avanço da ciência e tecnologia. Porto Alegre: Bookman, 2015.

GIL, A. Como elaborar projetos de pesquisa. 4, ed. São Paulo: Atlas, 2002.

HOLMSTRÖM, J.; KETOKIVI, M.; HAMERI, A. P. Bridging practice and theory: a design science approach. Decision Sciences, [S. l.], v. 40, n. 1, p. 65-87, 2009.

KIM, C. et al. On-site construction management using mobile computing technology. Automation in Construction, v. 35, p. 415-423, nov. 2013.

MAHAMID, I.; BRULAND, A.; DMAIDI, N. Causes of delay in road construction Project. Journal of Management in Engineering, Virginia, v. 28, n. 3, p. 300-310, 2011.

OLIVEIRA, A. A. R. de; LEITE FILHO, C. A. P.; RODRIGUES, C. M. C. O processo de construção dos grupos focais na pesquisa qualitativa e suas exigências metodológicas. In: ENCONTRO NACIONAL DOS PROGRAMAS DE PÓSGRADUAÇÃO E PESQUISA EM ADMINISTRAÇÃO, 31., 2007, Rio de Janeiro. Anais [...]. Rio de Janeiro: ANPAD, 2007. p. 1-15.

RICHARDSON, R. J. Pesquisa social: Métodos e Técnicas. 3rd ed. São Paulo, SP: Atlas, 2011.

SU, G. Obras rápidas de varejo: caracterização e proposta de diretrizes e produtos para planejamento e controle de tempos. Dissertação (Mestrado) - Programa de Mestrado em Ciências. Universidade de São Paulo, 2019.

YIN, R. K. Estudo de caso: planejamento e métodos. 4. ed. Porto Alegre: Bookman, 2010. 